\section{Knocking out the target in rats}

\section{By Steve Edelson, Executive Editor}

Despite the genetic similarity between rat and mouse, knockouts in the latter are commonplace whereas progress with knockout rats has lagged behind. Indeed, none of the gene deletions in rats have been targeted. Now, Open Monoclonal Technology Inc. (OMT) and collaborators including Sangamo BioSciences Inc. have reported a new way of making knockout rats in a targeted fashion. ${ }^{1}$

The application of zinc finger technology not only opens the potential to replace mouse-generated $\mathrm{mAbs}$ but may enable targeted gene deletion in any mammal.

OMT plans to use the rats to develop a human antibody generation platform that would allow companies to avoid the royaltystacking associated with mouse platforms for human $\mathrm{mAb}$ generation. Sangamo, meanwhile, thinks the ability to create targeted knockouts with its technology should be applicable to numerous species of mammal.

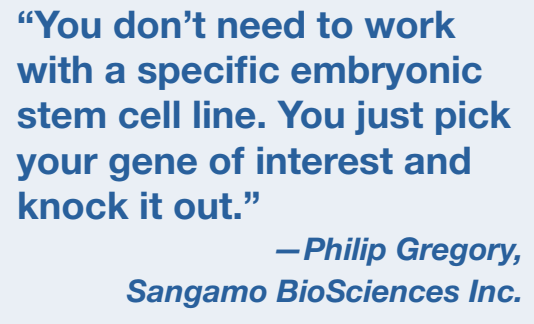

But in 2007, before a deal could be signed, THP's investors sold the company to Roche for $\$ 56.5$ million. Buelow rekindled the talks after founding OMT, and last year the company received a nonexclusive worldwide license to use Sangamo's zinc finger DNA-binding protein (ZFP) gene-targeting technology to develop and commercialize transgenic animals. The deal was exclusive for certain rat immune-system genes.

"I wasn't sure whether a zinc finger nuclease would work, because inducing a double-stranded DNA break can be lethal to a cell," noted Buelow.

The answer, according to results published in today's issue of Science, was yes. Researchers microinjected ZFNs into embryos and knocked out a rat's IgM genes with a success rate of about $10 \%-30 \%$. In addition, the majority of the mutant rats transmitted the deletion to their offspring. Moreover, there were no off-target deletions, confirming that the ZFN cut only at the desired IgM location.

In addition to OMT and Sangamo, authors on the Science paper included researchers from the Medical College of Wisconsin, Sigma-Aldrich Corp. and Institut National de la Santé et de la Recherche Médicale (INSERM).

The authors wrote that the "ZFN-driven gene disruption and germline transmission can be accomplished in 4 months' time." Gregory said this represents "six to ten months of time saving" compared with generating knockout

In addition, he said, "you don't need to mice via ESCs. to knock out rat genes. In mice, the closest system to rats, the process starts with embryonic stem cells (ESCs), in which a construct is introduced and through homologous recombination deletes a desired gene.

Even in mice, however, the process is far from optimized. "Mouse embryonic stem cell efficiencies are very low," said Philip Gregory, VP of research at Sangamo. "In addition, techniques for knockout mice require embryonic stem cells that are permissive to the process of gene targeting"; otherwise, the process will destroy the cells.

In rats, noted Gregory, "the field has been in hot pursuit of embryonic stem cells-we know where the cells should exist, but the questions are whether they'll grow in a tissue culture dish, can be grown out and allow for gene targeting."

Instead of attempting ESC manipulation, OMT CEO Roland Buelow opted for a different approach: microinjection of Sangamo's zinc finger nucleases into embryos. ZFNs induce targeted, double-strand breaks in DNA that can be used to clip specific genes out of a genome.

Buelow got the idea for using ZFNs at his previous company, antibody developer THP Inc. "At THP, I was thinking 24/7 about how to make knockout animals," Buelow said. "In 2005, I ran across papers on zinc finger nucleases. I approached Sangamo and started negotiating a deal." work with a specific embryonic stem cell line. You just pick your gene of interest and knock it out. The flexibility of creating these genetic changes is very important. It not only improves the speed of making a knockout, but doing so for any genetic background is very valuable."

\section{The mAb connection}

For OMT, the creation of the knockout rat was the major hurdle in the company's effort to produce human mAbs in the rodents. "The biggest unknown was whether we could actually get the knockout," said Buelow.

The company chose rats for several reasons. Buelow noted the animals breed rapidly and have well characterized immune systems. In addition, he said, "they're cheap to maintain and we already know how to make hybridomas," which is a key step in generating a line of rats that produces human mAbs against a desired target.

In addition, producing human $\mathrm{mAbs}$ in rats would allow a company to avoid owing royalties to the handful of companies with IP covering human mAbs from mice.

By year end, Buelow expects OMT will be ready to start making human mAbs against targets provided by would-be partners.

Upon completion of the platform, Buelow said, the company will be looking for a buyer. "My preference is to sell the company-I'd rather spend \$10-\$20 million to build a platform than spend \$100 million to 
build an entire company," he said. "You need good targets to succeed as an antibody company, and all the big guys are out there looking for targets. I want to avoid competing with them."

While OMT is busy trying to turn the rat into a human antibody factory, Sangamo and partner Sigma-Aldrich think that rat models of disease could offer advantages over mouse models. Sigma-Aldrich has commercialization rights to Sangamo's ZFNs for research purposes.

"The rat is believed to be a better physiological model than a mouse in representing the efficacy and side effects of a drug candidate," said Gregory. "Also, mice have limitations in terms of the type of disease for which they are useful. For example, a mouse is not very good at learning tasks like solving a maze. A rat is a much better model here," which could help better study neurological-deficit disorders such as Alzheimer's disease and Parkinson's disease.

Beyond rats, Gregory told SciBX the zinc finger nuclease approach "allows the targeted knockout of a specific gene [in an organism] for which there are no embryonic stem cells." He thinks the use of ZFNs could replace the current process for generating knockout mice.

"This finding could transform the existing mouse capabilities of every academic facility," added David Smoller, president of Sigma's research biotech business unit. "Right now a researcher can order a zinc finger nuclease and make a transgenic knockout in their lab."

Smoller said Sigma is considering "options and potential collaborations for producing new disease models. We're currently concentrating on the reagents that help produce the animals. Animals themselves are a bigger issue, but at minimum we'll collaborate with people that produce the knockout animals."

Edelson, S. SciBX 2(27); doi:10.1038/scibx.2009.1100

Published online July 23, 2009

\section{REFERENCES}

1. Geurts, A. et al., Science; published online July 23, 2009; doi:10.1126/ science. 1172447

Contact: Howard Jacob, Medical College of Wisconsin, Milwaukee, Wis. e-mail: jacob@mcw.edu

Contact: Roland Buelow, Open Monoclonal Technology Inc., Palo Alto, Calif.

e-mail: rbuelow@omtinc.net

\section{COMPANIES AND INSTITUTIONS MENTIONED}

Institut National de la Santé et de la Recherche Médicale, Paris, France Medical College of Wisconsin, Milwaukee, Wis.

Open Monoclonal Technology Inc., Palo Alto, Calif. Roche (SIX:ROG; OTCQX:RHHBY), Basel, Switzerland Sangamo BioSciences Inc. (NASDAQ:SGMO), Richmond, Calif. Sigma-Aldrich Corp. (NASDAQ:SIAL), St. Louis, Mo. 